\title{
BMJ Open Association of professional identity, gender, team understanding, anxiety and workplace learning alignment with burnout in junior doctors: a longitudinal cohort study
}

\author{
Lynn V Monrouxe, ${ }^{1,2}$ Alison Bullock, ${ }^{3}$ Hsu-Min Tseng, ${ }^{1,4}$ Stephanie E Wells ${ }^{5}$
}

To cite: Monrouxe LV, Bullock A, Tseng H-M, et al. Association of professional identity, gender, team understanding, anxiety and workplace learning alignment with burnout in junior doctors: a longitudinal cohort study. BMJ Open 2017;7:e017942. doi:10.1136/ bmjopen-2017-017942

- Prepublication history and additional material for this paper are available online. To view these files, please visit the journal online (http://dx.doi org/10.1136/bmjopen-2017017942).

Received 27 May 2017 Revised 24 October 2017 Accepted 25 0ctober 2017

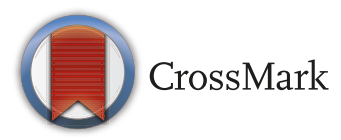

${ }^{1}$ Chang Gung Medical Education Research Centre (CG-MERC), Chang Gung Memorial Hospital Linkou Branch, Linkou, Taiwan ${ }^{2}$ School of Medicine, Chang Gung University, Linkou, Taiwan ${ }^{3}$ CUREMeDE, Cardiff University, Cardiff, UK

${ }^{4}$ Healthcare Management Department, Chang Gung University, Linkou, Taiwan ${ }^{5}$ School of Medicine, Cardiff University, Cardiff, UK

Correspondence to Professor Lynn V Monrouxe; monrouxe@me.com

\section{ABSTRACT}

Objectives To examine how burnout across medical student to junior doctor transition relates to: measures of professional identity, team understanding, anxiety, gender, age and workplace learning (assistantship) alignment to first post.

Design A longitudinal 1-year cohort design. Two groups of final-year medical students: (1) those undertaking end-ofyear assistantships aligned in location and specialty with their first post and (2) those undertaking assistantships non-aligned. An online questionnaire included: Professional Identity Scale, Team Understanding Scale, modified Hamilton Anxiety Rating Scale and modified Copenhagen Burnout Inventory. Data were collected on four occasions: (T1) prior to graduation; (T2) 1 month post-transition; (T3) 6 months post-transition and (T4) 10 months posttransition. Questionnaires were analysed individually and using linear mixed-effect models.

Setting Medical schools and postgraduate training in one UK country.

Participants All aligned assistantship ( $n=182)$ and nonaligned assistantship students $(n=319)$ were contacted; $\mathrm{n}=281(56 \%)$ responded: $68 \%(\mathrm{n}=183)$ females, $73 \%$ $(n=206) 22-30$ years, $46 \%$ aligned $(n=129)$. Completion rates: aligned $72 \%$ (93/129) and non-aligned $64 \%$ (98/152).

Results Analyses of individual scales revealed that selfreported anxiety, professional identity and patient-related burnout were stable, while team understanding, personal and work-related burnout increased, all irrespective of alignment. Three linear mixed-effect models (personal, patient-related and work-related burnout as outcome measures; age and gender as confounding variables) found that males self-reported significantly lower personal, but higher patient-related burnout, than females. Age and team understanding had no effect. Anxiety was significantly positively related and professional identity was significantly negatively related to burnout. Participants experiencing non-aligned assistantships reported higher personal and work-related burnout over time.

Conclusions Implications for practice include medical schools' consideration of an end-of-year workplace alignment with first-post before graduation or an extended shadowing period immediately postgraduation. How best to support undergraduate students' early professional
Strengths and limitations of this study

- The use of predefined and validated questionnaires enables our data to be considered alongside others' use of these scales.

- Linear mixed-effect models of burnout subscales enabled us to include participants with missing outcomes in the analyses (if sufficient data points), to treat time as continuous rather than a fixed set of points and easily handled time-invariant and timevarying covariates.

- Although respondents came from a range of UK medical schools, those experiencing an aligned assistantship were all trained and subsequently worked in a single UK country.

- This study comprises self-reported measures of anxiety, professional identity, team understanding and burnout.

identity development should be examined. Support systems should be in place across the transition for individuals with a predisposition for anxiety.

\section{BACKGROUND}

Medical students' transition into clinical practice has long been regarded as a period of high stress. During the first postgraduate year, medical graduates are required to adjust to the increased workload and responsibility of their new role in addition to coping with the challenges of frequently rotating between departments and managing uncertainty concerning their future career. ${ }^{1-5}$ Doctors' chronic exposure to workplace stress has been associated with mental health disorders and burnout: feeling mentally and physically exhausted due to work or caregiving undertakings. ${ }^{6-8}$ A higher prevalence of mental health disorders such as anxiety, depression, substance misuse and suicide among doctors and medical students is widely reported in 
the literature. ${ }^{8-10}$ Furthermore, studies conducted in Europe, ${ }^{11-14}$ North America, ${ }^{15-17}$ Australia, ${ }^{37}$ and South East Asia. ${ }^{18}$ have all highlighted burnout to be an area of international concern particularly in relation to its association with increased psychiatric morbidity and negative health behaviours among medical students and early career doctors. ${ }^{61119}$ The potential personal and professional consequences of mental health problems and burnout for doctors and their patients can be devastating, resulting in suboptimal patient care, increased medical errors and lapses in professional behaviour. ${ }^{1720-22}$

Mental health problems and burnout observed at undergraduate level have potential implications for graduates' following their transition into clinical practice. For example, perceived stress during medical school has been shown to be a predictor of mental health problems requiring treatment among postgraduates. ${ }^{23}$ In addition, doctors at the start of their postgraduate training have been found to be at increased risk of developing burnout compared with their more senior counterparts. ${ }^{24}$ This in part may be attributable to an undergraduate burnout hangover, as a number of studies have suggested that graduates commence their postgraduate training already exhibiting features of burnout. ${ }^{11} 121624$ However, a longitudinal prospective cohort study of 117 final year students found a steady increase in burnout over time, rising from $28 \%$ prevalence at T1 (6 months prior to graduation) to $75 \%$ at T5 (11 months postgraduation). ${ }^{26}$ This suggests that the workplace learning environment also has an impact. Likewise, a more recent study examining medical interns in an Australian hospital found a $60 \%$ overall incidence of burnout and reported similar longitudinal findings whereby high levels of personal and work-related burnout were recorded throughout the year, peaking at 6 months into the internship. ${ }^{27}$

\section{INDIVIDUAL FACTORS AND BURNOUT: IDENTITY, TEAM UNDERSTANDING AND ANXIETY}

It has been argued that burnout in doctors is mainly due to personal factors, including trait measures of personality and individual perceptions of the learning and work environment. ${ }^{28}$ The professional socialisation of medical students has been the focus of much study recently. ${ }^{29-32}$ Essentially, it has been argued that in order to behave as a fully functioning member of the medical profession, medical students need to develop a strong sense of themselves as doctors. ${ }^{30-32}$ Thus, an essential part of becoming a doctor comprises students' identification of themselves as being part of the medical profession: ${ }^{29} 303233$ that is, developing an embodied professional identity that links them with the group. Additionally, identity threat has been significantly correlated with burnout in doctors. ${ }^{34}$ Given that the group is part of our identity, and we are part of the group, identity threats can include feeling that the group we identify with is threatened in some way or feeling alienated from the group (disrupting our sense of belonging) ${ }^{35}$ The ability to work well within a team and the opportunity to have a strong sense of belonging to the group (eg, working in teams during work-based learning placements) have been highlighted as facilitating factors for group identification. ${ }^{29}$ Anxiety can be generated by virtue of the situation or event in which we might find ourselves (so once the source of 'threat' goes away, so does the experience of anxiety). ${ }^{36}$ Anxiety can also be a more generalised attribution of an individual. ${ }^{37}$ Research has demonstrated an association between generalised anxiety and burnout in doctors and other healthcare professionals. ${ }^{38-40}$

\section{MOVING FROM INDIVIDUAL TO INSTITUTIONAL FACTORS FOR BURNOUT}

There have been calls for increased interventions targeted to address well-being, mental health problems and burnout at both the undergraduate and the postgraduate level. ${ }^{624}$ Moreover, there has been a call to focus on both individual and organisational factors that might contribute to well-being, rather than purely constructing burnout as a personal failing. ${ }^{41}$ The most commonly studied interventions for physicians involve mindfulness, stress management and the use of small group discussions. ${ }^{42}$ Although such interventions have been shown to be beneficial for reducing physician burnout, ${ }^{42}$ they all continue to focus the problem solely at the individual level.

In terms of the environmental level, research has found that students experiencing hospital rotations are more likely to report burnout than those experiencing outpatient, consult services, intensive care or research rotations. ${ }^{43}$ Students on rotations requiring overnight call were also significantly more likely to report burnout ( $55 \%$ vs $45 \%$ ) than students not on rotations requiring overnight call. ${ }^{43} \mathrm{~A}$ recent systematic review, however, has focused on learning environment interventions and their impact on medical students' emotional well-being. ${ }^{44}$ A total of 28 articles were identified with interventions targeted at both individual and institutional levels, including: mental health programme, mind-body skills training, wellness programmes, mentoring, programme reform and curriculum structure. ${ }^{44}$ Regarding curricula structure, one study reported that students whose clinical contact hours comprised a greater percentage of their overall learning experiences were less likely to experience burnout or to have seriously considered leaving medical school. ${ }^{45}$ This suggests that work-based experience might be a mitigating factor for burnout as students transition into practice.

\section{CURRICULA INTERVENTION}

In 2009, the UK General Medical Council introduced a compulsory new addition to the undergraduate curricula in the form a work-based transitional intervention; the assistantship programme. ${ }^{46}$ Assistantships are designed to address preparedness for practice concerns and the 
peak in patient safety-related incidents as final year students transition into becoming junior doctors ${ }^{47-49}$ and are defined as placements in which final year medical students 'act as assistant to a junior doctor, undertaking defined duties under appropriate supervision, ${ }^{50}$ Thus they comprise end-of-course work-based experiences with the specific aim of smoothing students' transition into practice.

There is growing evidence that supports the efficacy of these placements in: improving graduates' preparedness for practice across a range of clinical and non-clinical skills domains, ${ }^{51}{ }^{52}$ facilitating a graduated increase in responsibility ${ }^{53-56}$ and providing opportunities for gradual, low-stress workplace acclimatisation and integration within clinical teams facilitated by assistantship alignment. ${ }^{485}$ However, much of the data to support these assertions lacks rigour. For example, in the case of questionnaire studies, each one uses a different questionnaire with slightly different foci of enquiry: student anxiety, ${ }^{55}$ learning opportunities ${ }^{5657}$ and specific skills' confidence. $^{51} 52$ Additionally, respondent numbers are generally low (eg, $\mathrm{n}=37$ and $\mathrm{n}=43$ at time 1 ), ${ }^{52} 57$ with none of the analyses matching participant data longitudinally from time 1 (T1) and time 2 (T2). Finally, there is no single model of assistantship: each programme has a different duration (2 weeks, 4 weeks, 8 weeks and so on), placements are provided at different times in the curricula (before and after final examinations) and different in configurations (aligned to the first post on graduation or non-aligned).

Taken together this makes it difficult to draw any strong conclusions regarding the efficacy of the assistantship period. No one study builds on another. Moreover, to date, there has been a limited exploration of the longer-term consequences of assistantship alignment on graduates' psychological well-being, namely whether assistantship alignment serves as an existing curriculum intervention to reduce levels of anxiety and burnout in newly qualified doctors. We therefore aim to fill these gaps in the literature through our mixed-methods longitudinal programme of research. Specifically, this study focuses on the following research questions:

\section{RESEARCH QUESTIONS (RQS)}

RQ 1: Do self-reported professional identity, anxiety, team understanding and burnout levels change over time as final year students transition into clinical practice?

RQ 2: Are there any associations between assistantship alignment and self-reported professional identity, anxiety and team understanding on burnout scores over time?

\section{METHODS}

A longitudinal 1-year cohort design was used with data being collected via an online questionnaire. The questionnaire included the Professional Identity Scale, ${ }^{29} 58$ the Team Understanding Scale, ${ }^{29}$ the modified Hamilton
Anxiety Rating Scale S $^{59}$ and the modified Copenhagen Burnout Inventory. ${ }^{60}$ The professional identity scale comprises nine questions relating to an individuals' perception of their group identification, the team understanding scale measures students' understanding of team working and willingness to engage. The professional identity and team understanding scales have been successfully validated with a health and social care student population, including medical students. ${ }^{29}$ The Hamilton Anxiety Rating Scale includes a series of statements concerning individuals' experience of anxiety-related symptoms and is essentially a measurement of a person's general anxiety responsiveness, rather than a measure of context-specific anxiety. We used this scale to understand how an individuals' level of anxiety impacts on burnout thus facilitating a better understanding of the impact of the assistantship (as an environmental factor) on burnout levels. The Copenhagen Burnout Inventory comprises questions in three domains: personal burnout, patient-related burnout and work-related burnout and has been validated for the assessment of burnout in hospital doctors ${ }^{60}$ and undergraduate students. ${ }^{61}$ The versions of the Hamilton Anxiety Rating Scale and Copenhagen Burnout Inventory included in the questionnaire were slightly modified by the addition of personal prefixes for example, 'I feel.../I experience...'. Owing to a transcription error in the process of generating the online questionnaire, one personal burnout question ('I feel weak and susceptible to illness') was not included in the questionnaire (see online supplementary appendix A for the full version of all scales used). The questionnaire comprised 16 pages including one introduction, three demographic/background pages, a 'your story' page, a 'prize draw' page and a final summary page. Participants could not move forward without completing sections (apart from the final 'your story' section) but could move backwards. This study was conducted as part of a wider, longitudinal, mixed-methods programme of research to examine emotional issues around graduates' transition into practice. ${ }^{48}$

\section{Context}

All medical students in Wales undertake a 6-7week student assistantship with both medical schools co-operating to provide a countrywide joined-up approach. For undergraduates who will commence their postgraduate training in Wales, their assistantship is aligned in location and specialty with their first postgraduate role as a junior doctor (known variously internationally as the intern, PGY1 or first residency year) post. This first post is not necessarily in the same location within the country. For example, the graduate could be starting their new junior doctor post in a remote northern Wales setting despite them undertaking the majority of their studies in a southern city setting. Welsh undergraduates who will commence their first post in another UK region and undergraduates from other UK medical schools who will commence their first post within Wales undertake non-aligned assistantships. Some of these graduates might 
be returning to their home country, Wales. This context provides us with a natural experiment situation, with both groups of participants likely experiencing some form of disruption to their social setting.

\section{Procedure}

Following ethical approval, all 2015 graduates of the two medical schools in Wales were invited to participate $(\mathrm{n}=351)$ along with graduates from other medical schools who would commence working as a doctor within Wales $(\mathrm{n}=150)$. Within this cohort, participants fell into two groups: (1) aligned assistantship: individuals who experienced the student assistantship aligned with their first post and (2) non-aligned assistantship: individuals who experienced the student assistantship in a different place to their first post. In the UK, the first post is the start of Foundation training, Foundation Year 1 (FY1).

Questionnaires were hosted and administered via the Bristol Online Survey (BOS). Undergraduate assistants tested the questionnaire prior to administration (see Acknowledgements section). Invitations to participate in the study were sent to graduates via email with the assistance of undergraduate (T1) and postgraduate (T2-T4) administrators. Weekly reminder emails were sent. A link to the questionnaire was posted on targeted social media pages: for example, undergraduate year group/junior doctor Facebook pages. As an incentive for participation, individuals were offered the chance to be entered into a prize draw (thirty $£ 20$ vouchers were available for each questionnaire). To facilitate delivery of the vouchers, participants wishing to enter the draw were asked to provide an email address. With participants' consent, their email address was used as a data identifier allowing participants' responses to be paired over time and analysed longitudinally. After the data had been aligned, all identifiers were removed, and statistical analyses was performed anonymously (SEW only had access to this data). Participants were invited to complete the online questionnaire on four occasions between June 2015 and June 2016: (T1) prior to graduation from medical school and in the middle of their assistantship period (8 June- 6 July 2015); (T2) 1 month following their transition into clinical practice (1-30 September 2015); (T3) 6 months after their initial transition into clinical practice and 2 months after their second post (4 January-4 February 2016) and (T4) 10 months following their initial transition and 2 months after their third post (23 May-24 June 2016). These time periods were purposively designed to capture these other transitions in the junior doctor first year (ie, transitioning into new specialties). We did not use the facility within the BOS to enable individuals to 'save responses and complete later', so we are unable to know how many people started, but did not finish, the questionnaires.

\section{Data analysis and stability assessment}

Analysis comprised two stages. Stage 1 analyses was undertaken to answer RQ1 in terms of whether self-reported professional identity, anxiety, team understanding and burnout levels changed over the time of our study as final year students transitioned into their clinical practice. Here, the individual scales were examined (for the Copenhagen Burnout Inventory the three subscales of burnout were examined separately: personal, patient-related and work-related). The significance of the main effects (alignment group and time) and the interaction effects for aligned/non-aligned groups over time were assessed with the Wald $\mathrm{X}^{2}$ test using generalised estimating equation.

Stage 2 analyses were undertaken to answer RQ2 by examining the associations between assistantship alignment, self-reported professional identity, anxiety and team understanding on burnout scores over time. Multivariate regression analyses were performed by fitting the data to a mixed-effect model. ${ }^{62}$ The majority of the results were analysed using $\mathrm{R}^{63}$ and lme $4 .{ }^{64}$ We performed linear mixed-effect models on the three factors of burnout (personal, patient-related and work-related) to assess the effect of alignment, phase and interaction on burnout. The mixed-effect model was chosen as it offered a better fit of the data than the repeated measures analysis of variance for these data sets. Mixed-effect models allow individual variability to be accounted for by computing a random slope and a random intercept for each participant. In this way, individual differences in subjective burnout levels were accounted for. The random effect components comprised: (1) intraindividual variation on burnout throughout the different time points and (2) measurement error (ie, the remaining 'noise' in the model that represents unexplained variations not captured by the model).

We treat time as a continuous variable. We hypothesised that the degrees of burnout change over time could be partly predicted by participants' experiences of assistantship alignment as well as their personal characteristics of anxiety responsiveness, professional identity and perceived support from team understanding. To assess the impact of other factors on the participants' burnout, confounding factors such as participants' age and gender were included in the fixed effect components. As these factors may cause the burnout to be higher or lower or they may cause the burnout to change at a faster or slower rate across time, such variation was modelled with a random intercept and slope, respectively, for each participant. Although it is interesting to see the interaction between these factors and time, we do not include these interaction terms in our model for simplicity purpose. The notations in the model are as follows:

$$
\begin{gathered}
\text { Burnout }_{i j}=\mu+\beta_{g} \text { Group }_{j}+\beta_{t} \text { Time }_{i}+\beta_{\text {gt }} \text { Group }_{j} \times \text { Time }_{i}+\beta_{s} \text { Gender }_{j} \\
+\beta_{a} \text { Age }_{j}+\beta_{x} \text { Anxiety }_{j}+\beta_{p} \text { PI }_{j}+\beta_{w} \text { Team Understanding }_{j} \\
+\gamma_{j}^{0}+\gamma_{j}^{1} \text { Time }_{i}+\epsilon_{i j}
\end{gathered}
$$

where $\mathrm{i}$ indexes the time phase and $\mathrm{j}$ indexes the individual. With respect to effect size of linear mixed 
Table 1 Number (and \%) of respondents' demographics across each of the four data collection times

\begin{tabular}{|c|c|c|c|c|}
\hline & T1 & T2 & T3 & T4 \\
\hline Group & 208 & 175 & 135 & 125 \\
\hline Aligned & 99 & 79 & 64 & 65 \\
\hline \multicolumn{5}{|l|}{ Gender } \\
\hline Female & 135 (64.9) & $120(68.57)$ & 93 (68.89) & 87 (69.6) \\
\hline \multicolumn{5}{|l|}{ Age (years) } \\
\hline $17-25$ & 155 (74.52) & $129(73.71)$ & $96(71.11)$ & 98 (78.4) \\
\hline $26-30$ & 45 (21.63) & $40(22.86)$ & 36 (26.67) & 24 (19.2) \\
\hline $31-35$ & 4 (1.92) & $4(2.29)$ & $2(1.48)$ & $3(2.4)$ \\
\hline $36-40$ & $4(1.92)$ & $2(1.14)$ & $1(0.74)$ & $0(0)$ \\
\hline
\end{tabular}

models, we employed the method for obtaining $\mathrm{R}^{2}$ from generalised linear mixed-effects models developed by Nakagawa and Schielzeth. ${ }^{65}$ This method yields two $\mathrm{R}^{2}$, a marginal $R_{m}^{2}$ that accounts for the variance explained by the fixed factors and a conditional $\mathrm{R}_{\mathrm{m}}^{2}$ for the variance explained by both fixed and random factors.

\section{RESULTS}

\section{Characteristics of respondents}

The response rates for the four time points were as follows: T1 n=251 (50\%), T2 n=179 (34\%), T3 n=141 (28\%) and $\mathrm{T} 4 \mathrm{n}=125(25 \%)$. The response rate aggregated over time was $56 \%(n=281)$, of whom $68 \%(n=183)$ were female and $73 \%(\mathrm{n}=206)$ were aged $12-30$ years. Among these, $\mathrm{n}=129 \quad(46 \%)$ experienced the aligned assistantship. Ninety respondents completed the questionnaire on only one occasion. Given this is a longitudinal study, the criteria for inclusion was participation at more than one time. The data from these 90 participants were therefore excluded from the analyses. The number and characteristics of respondents that fulfilled the inclusion criteria at each time point are outlined in table 1. Completion rates of $72 \%$ (93 of 129) and 64\% (98 of 152) were observed for aligned and non-aligned participants, respectively. Incomplete data were accounted for in the analyses via maximum likelihood estimation. This difference in study completion did not differ significantly between the two groups, $\mathrm{X}^{2}(1)=1.53, \mathrm{p}=0.22$. The percentages of female by time phase were $65 \%, 69 \%, 69 \%$ and $70 \%$, respectively $\left(\mathrm{X}^{2}(3)=1.1, \mathrm{p}=0.22\right)$.

\section{Anxiety, professional identity, team understanding and burn- out over time}

We begin by considering RQ1: do self-reported professional identity, anxiety, team understanding and burnout levels change over time as final year students transition into clinical practice? The changes in self-reports of anxiety, professional identity, team understanding and burnout (personal, patient-related and work-related burnout) by assistantship alignment group over time are displayed in table 2. Briefly, self-reported anxiety levels and professional identity remained stable throughout the four time points. Team understanding scores increased significantly over time. Concerning the measures of burnout, all three subscales (personal, patient-related and work-related burnout) increased sequentially across the four time points, although this did not reach significance for patient-related burnout. We found no significant differences for any of the measures taken by alignment group nor any interactions between time and alignment group for these measures.

\section{Linear mixed-effect model of alignment on burnout longitudinally}

We now consider RQ2: Are there any associations between assistantship alignment, self-reported professional identity, anxiety scores and team understanding on self-reported burnout scores over time? Table 3 shows the results of the mixed-effect model with the parameter estimates for factors affecting components of modified Copenhagen Burnout Inventory (ie, personal, patient-related and work-related burnout). By looking at the random effect components, similar patterns were observed for all three subscales of burnout. The intercepts for three components of burnout are significant while the slopes were insignificant. That is, the variance in change in burnout by time points (as indicated by slope) is relatively small while the variation in each component of overall burnout between individuals (as indicated by intercepts) is quite large. Thus, the size of the intercepts is likely to be due to individual differences in burnout. This pattern is not uncommon for self-report questionnaires aiming at stable characteristics such as burnout.

From the parameter estimates of the fixed effect components, similar patterns were again observed for all three components of burnout. Over time, burnout scores increased as indicated by increasing trend in the time parameter estimates at subsequent time points, which is significant for work-related burnout $(\beta=1.62$, $\mathrm{P}<0.01)$. For personal characteristics, the significant 


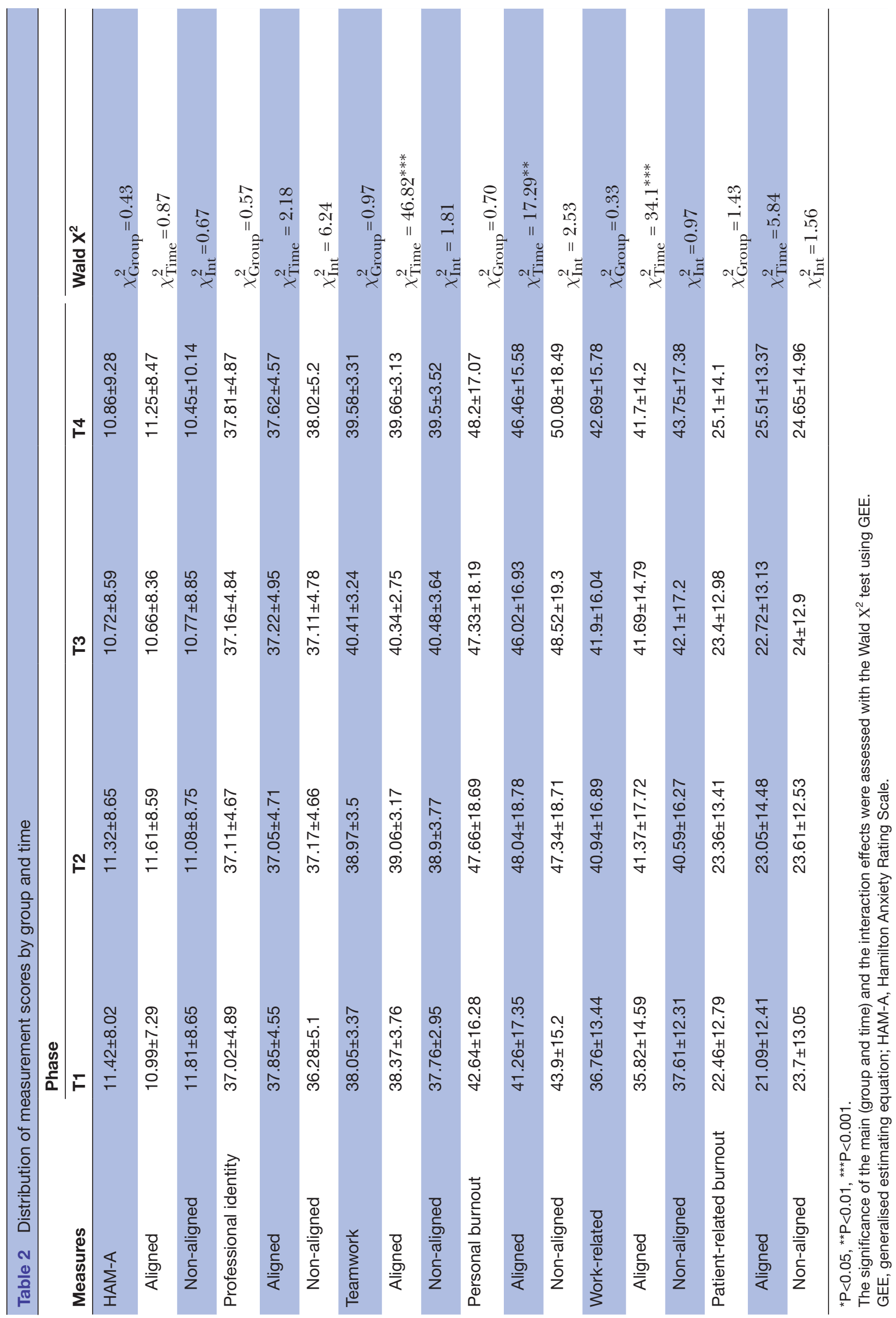


Table 3 Results of mixed-effect models

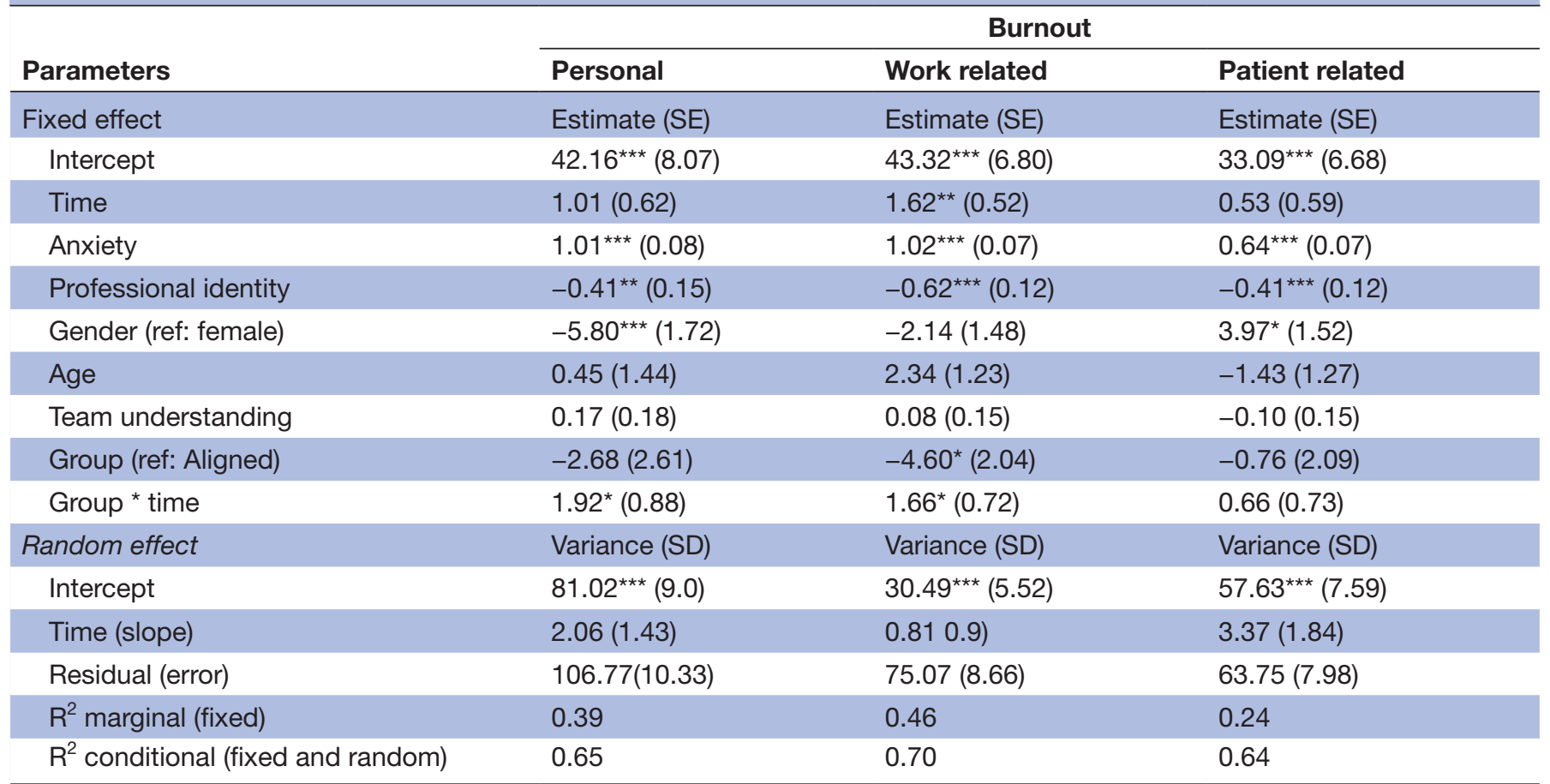

${ }^{*} \mathrm{P}<0.05,{ }^{* \star} \mathrm{P}<0.01,{ }^{* * *} \mathrm{P}<0.001$.

The significance of the fixed effect was assessed with the Wald test conducted on the full model, whereas the significance of the random intercept and slope effects was assessed with likelihood testing using residual maximum likelihood (REML) estimation. For each components

of burnout, the corresponding marginal and conditional $R_{G L M M}^{2}$ values were computed based on the method developed by Nakagawa and Schielzeth. ${ }^{65}$

main effects were found for anxiety and perceived professional identity. The significant main effect for anxiety (personal burnout: $\beta=1.01$, work-related burnout: $\beta=1.02$, patient-related burnout: $\beta=0.64$, all $\mathrm{P}<0.001$ ) indicates that individuals with high self-reported anxiety levels reported greater burnout than did those with low self-reported anxiety levels. However, the reverse relationships were found for perceived professional identity and burnout (PB: $\beta=-0.41 \quad(\mathrm{P}<0.01)$, work-related burnout: $\beta=-0.62$, patient-related burnout: $\beta=-0.41$ (both $\mathrm{P}<0.001)$ ). Gender also had a significant effect on personal burnout $(\beta=-5.8, \mathrm{P}<0.001)$ and patient-related burnout $(\beta=3.97, P<0.05)$, but not significant for work-related burnout $(\beta=-2.14, p=0.15)$ : Males self-reported significantly lower personal burnout, but higher patient-related burnout scores than females. Age and team understanding did not affect burnout scores.

The main effect of alignment group is superseded by the significant interaction between alignment and time for personal burnout $(\beta=1.92, \mathrm{P}<0.05)$ and work-related burnout $(\beta=1.66, \mathrm{P}<0.05)$. The aligned assistantship participant group, the reference group, self-reported personal burnout scores increased and an average of 1.01 per time point (see figure 1). For the non-aligned assistantship group, self-reported personal burnout scores increased $2.93(1.01+1.92)$ per time point on average. Similarly, self-reported work-related burnout scores increased an average of 1.62 per time point for the aligned assistantship group and an average of 3.28 per time point for the non-aligned assistantship group. However, when the actual scores by phase are plotted, we can see how the aligned assistantship respondent group demonstrated asymptote, peaking at time 3 (6 months post-transition) whereas the non-aligned assistantship group demonstrated asymptote at time 4 .

\section{DISCUSSION}

To our knowledge this is the first study to have examined how both individual and environmental factors affect junior doctors' burnout over time. Our longitudinal cohort study used a range of validated questionnaires designed to examine whether medical students' participation in an end-of-year placement (assistantships aligned or non-aligned with their first junior doctor post), along with their self-reported professional identity, team understanding and anxiety, related to their self-reported burnout over time. Looking at the questionnaires individually, we found that team understanding, personal burnout and work-related burnout increased significantly over time irrespective of respondents' alignment experience, but no increase in patient-related burnout. This finding has some similarity with other research. For example, a longitudinal cohort study of medical graduates in Australia found that personal burnout and work-related burnout rose significantly over their first year, although 


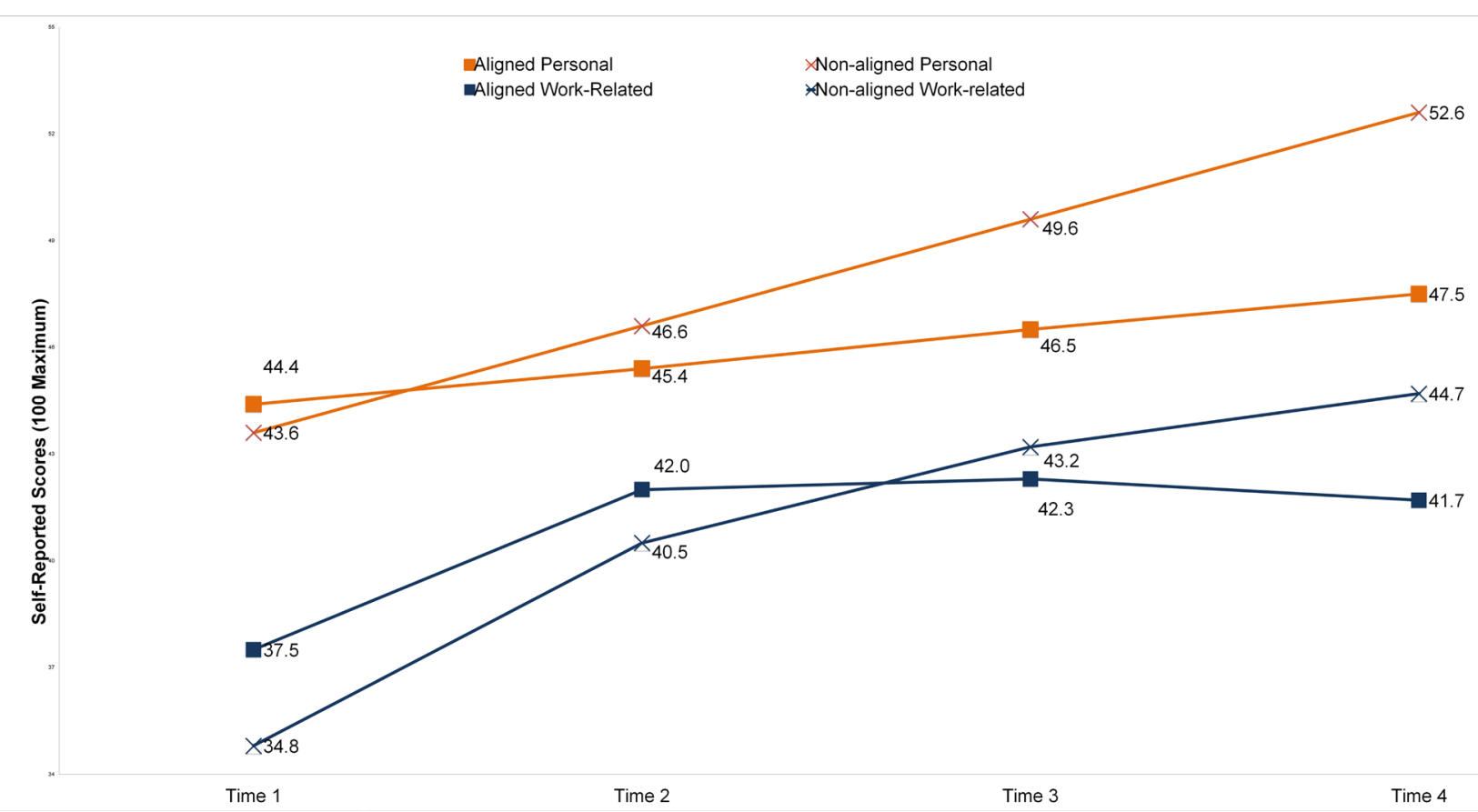

Figure 1 Assistantship alignment and time: association with personal and work-related burnout.

unlike our study these peaked at 6 months. ${ }^{27}$ Furthermore, patient-related burnout remained at significantly lower levels than personal burnout and work-related burnout, although it demonstrated a significant increase at 12 months from the 'no-change' earlier time periods. ${ }^{27}$ Professional identity and anxiety did not change significantly across the four time periods in our study, again, irrespective of assistantship alignment.

The findings around professional identity, team understanding and burnout suggest that assistantship alignment appears to provide no absolute beneficial effect on these factors for individuals whose work-based placements are intimately associated with their first role as a junior doctor. This runs counter to our expectation that an aligned assistantship would be beneficial in these areas. However, employing a linear mixed-effect model using burnout as the outcome variable, we found a significant relationship between alignment group and time for personal burnout and work-related burnout. Respondents experiencing a non-aligned assistantship reported a sharper rise (threefold) in personal burnout across all four time-points than those experiencing an aligned assistantship with neither group showing evidence of reaching asymptote. A similar rise was found for the non-aligned assistantship group and work-related burnout, although work-related burnout reached asymptote for the aligned assistantship group immediately on transition into practice. This suggests a slightly delayed beneficial effect regarding work-related burnout for aligning work-based placements to students' first post as a junior doctor. Furthermore, this beneficial effect continues beyond junior doctors' first post and throughout subsequent transitions in the first year. That the aligned group demonstrated an initial rise in work-related burnout on their first transition to being a junior doctor is not unexpected. Indeed, the sharp rise in responsibility as perceived by new graduates is well documented $^{483}$ and it is highly possible that students undertaking an aligned assistantship might feel more protected prior to their first post beginning. ${ }^{48}$ As such, there might be an initial 'shock' at first, followed by a period of greater stability.

Our linear mixed-effect model also identified an association between anxiety and burnout: respondents reporting high anxiety levels also reported higher burnout scores as compared with those reporting low anxiety levels. This finding resonates with other research examining the relationship between anxiety and burnout in healthcare professionals. ${ }^{3940}$ Taken together with our finding, it suggests that individuals with a predisposition for anxiety are more likely to self-report burnout. Interestingly, the reverse relationship was found for perceived professional identity in our study: higher levels of self-reported professional identity were related to significantly lower self-reported burnout across all three factors. As such, our finding relates to other studies examining the relationship between identity and burnout in healthcare workers, teaching professionals, the general population as well as experimental research on members of the general population undertaken by social psychologists. ${ }^{66-69}$ Indeed, such research has suggested that a strong sense of social identity (ie, a feeling of belonging to the group) facilitates an increased capacity to cope under stress and that a failure to develop such a shared identity is associated with a reduced ability to deal with stressors effectively. ${ }^{66}$ That self-reported identity did not change over time in our study suggests that for some, this shared identity might have been already sufficiently formed prior to students' transition into practice, and that any protective effect that 
it provides has not been diminished (or enhanced) by the assistantship alignment experience and their subsequent junior doctor role. For those participants whose shared identity was insufficiently formed prior to their transition, it appears that such identities, likewise, are nether diminished or enhanced over time leaving them vulnerable to experiencing burnout. However, as we did not measure individuals' perceptions of their professional identities prior to the assistantship programme ( $\mathrm{T} 1$ being in the middle of it), we cannot be fully sure that the early weeks did not have an impact on professional identity.

Participant gender was also related to burnout scores in our study. Males reported significantly lower personal burnout, but higher patient-related burnout scores than their female counterparts. For work-related burnout, both groups demonstrated an increase over time. Regarding personal burnout, previous research suggests that the prevalence of mental health problems is higher in female doctors than their male counterparts, ${ }^{70}$ and other research on a graduate cohort have found females reporting greater personal burnout than males. ${ }^{27}$ It has been postulated that the vulnerability of females to burnout and mental health problems may be in part a reflection of the gender specific stresses females encounter in the workplace. ${ }^{71}$ However, evidence concerning the relationship between burnout and gender to date is inconclusive. While some studies have reported the prevalence of burnout to be higher in female doctors, ${ }^{772}$ other studies have reported no gender differences ${ }^{1}$ or a higher prevalence in males. ${ }^{1173}$

Our findings resonate with Hillhouse et al's model of work stress, burnout, affect, health and clinical competence regarding the higher level of patient-related burnout identified in male medical residents, ${ }^{74}$ although other research has not found this. ${ }^{27}$ Indeed, in the wider literature, the commonly held assertion that females are at higher risk of burnout than their male counterparts in the labour market generally has been challenged in a recent meta-analysis. ${ }^{73}$ One factor that might impact on these gender-specific findings might be that respondents are acting according to their gendered expectations. Thus males might downplay distress due to a social expectation that they should appear tough and resilient. ${ }^{75}$ Thus, in our study we find that males report greater patient-related burnout but females reporting greater personal burnout. In terms of the social expectations explanation, it could be that males are downplaying their personal burnout (subconsciously acting out a tough male role) but up playing patient-related burnout (ie, subconsciously shifting from self to 'other') and vice versa for females (ie, subconsciously due to societal expectations around their nurturing role). However, we remain agnostic on this interpretation, as it is impossible to really understand what is happening. Importantly, if it is that males are downplaying their experiences of personal burnout, they might be at greater risk of experiencing negative emotional well-being. As such we should not necessarily accept the findings in terms of gender at face value.
Despite having strong findings, our research has limitations that need to be taken into account when considering the implications of these findings for practice. First, although the respondents come from a wide range of medical schools across the UK, those experiencing an aligned assistantship were all trained and subsequently worked in a single UK country, Wales. This could be a potential confounding factor, whereby it could be argued that the interaction between burnout and alignment might purely be due to the change in location and the subsequent disruption to support networks and homes, rather than the work-based placement. However, this is unlikely as students' first posts in Wales were not necessarily located in the same place in which their undergraduate learning occurred. For example, those learning in one University hospital might have their first post in an entirely different one, even differing between city and rural locations across the country. Second, respondents were not randomised to the aligned or non-aligned workbased placements, and it might be that this 'natural experiment' has within it some further confounding factors. For example, there might be some similarities between those individuals who trained in Wales and who wish to stay there, which are very different to those who chose to work elsewhere or to those who trained elsewhere but wished to work in Wales. Third, our study respondents comprised a much higher ratio of females than males (2:1). This ratio, although generally reflecting the higher proportion of females than males in the UK graduate population, is rather exaggerated: the average percentage of woman to graduates over the past few years has been $56 \%$, which is lower than our study average $(68 \%){ }^{76}$

Despite these limitations, our research has notable strengths. The joined up nature of the assistantship programme in Wales has provided us with a unique opportunity to examine the effects of learning alignment to graduates' first post across a range of personal and environmental factors that are important for the well-being of our clinical workforce. We have been able to use a general linear mixed regression model, which has proved a useful approach for analysing our repeated measures data in this longitudinal cohort study. Although the model is similar in many respects to ordinary multiple regression, using the mixed regression analysis allows us more flexibility than an ordinary multiple regression: it enables us to include participants with missing outcomes in the analyses (so long as there are sufficient data points); it has permitted us to treat time as continuous, rather than a fixed set of points, and it can easily handle both time-invariant and time-varying covariates. As such we have been able to unpack the nuances to understand how these factors interact over time.

Our findings bring forth some implications for practice and future research suggestions. Given that graduates experiencing an aligned assistantship demonstrate a lower rise in personal burnout over the transition period and a stabilised work-related burnout as compared with those whose assistantship was non-aligned, we suggest 
that medical schools consider organising students' finalyear placements with their first-post on transition or that an extended shadowing period is explored immediately on graduation. Although this suggestion might seem out of reach, we believe that it is not impossible. For example, in 2016 across the UK an average of $40.5 \%$ of graduating medical students selected their local foundation school (the organisation which provides postgraduate training) as their first preference for postgraduate studies (with Northern Ireland and Scotland having over $60 \%$ of graduates applying locally), the vast majority of which were successful. ${ }^{77}$ This means that potentially around $40 \%$ of UK graduates could experience an aligned assistantship prior to their transition into practice. Such a move would enable further research on the potential benefits of alignment to be examined on a much wider scale.

Furthermore, given that possessing a strong professional identity appears to mitigate burnout and that identity does not appear to develop over the transition period, we suggest that educators might consider how best to support the professional identity of undergraduate students early on in their programme to ensure this is fully embodied at the time of graduation. ${ }^{78}$ It is important to note that such an identity appears to be associated with their feeling of belonging to the profession in general, rather than just to the specialty in which they are studying and will be working in. Therefore educational considerations need to focus on this aspect of affiliation. Finally, given the strong relationship between anxiety and burnout that has been identified in ours, and other studies, we suggest that support systems are in place for individuals who have a predisposition for anxiety. Such support systems should be operations during students' undergraduate years and should be made available to them as they transition into practice and beyond.

Following our study we have suggestions for future research. The majority of research in medical education to date has focused on individual factors responsible for burnout, yet we have identified a strong relationship between burnout and environmental factors (assistantship alignment). However, our research tells us little about what it is in the alignment/non-alignment experience that has facilitating/mitigating effects. As such we suggest that future research considers these "black box' issues and tries to unpack the nuances within. For this, qualitative methods (eg, interviews, diaries and video ethnography) as well as validated questionnaires alongside appropriate approaches to understanding the intricacies of the mechanisms that might be at play (eg, realist research, structural equation modelling and factor analysis). Furthermore, a concerted effort towards undertaking a systematic programme of research, where each study adds to and builds on, the other is required. Without such research our knowledge about the factors that increase and mitigate burnout in junior doctors will continue to be unnecessarily fragmented.
Acknowledgements The authors wish to thank the wider research team for their involvement in the study design, helping to secure funding ethics approvals and data collection (Michael Stechman, Tom Yapp, Anton Saayman, Steve Riley, Wyn Harris, Lori Black). In addition, the authors thank Nerys Jones and Hannah Perks for their assistance in testing the questionnaire.

Contributors LVM and AB contributed to the conception of the study; LVM, AB and SEW designed the work; SEW contributed to the acquisition of the data; H-MT and LVM contributed to the analysis of the data and all authors contributed to the interpretation of data; LVM and SEW drafted the manuscript, all authors revised the manuscript critically for important intellectual content; all authors gave their final approval of the version to be published; all authors agree to be accountable for all aspects of the manuscript and will ensure that any questions relating to the accuracy or integrity of any part of the manuscript are appropriately investigated and resolved.

Funding The study was partly funded by a small research grant from the Association of the Study of Medical Education (ASME) and partly by the School of Medicine, Cardiff University, who have been kept informed of progress with the collection, analysis and interpretation of data but the researchers remained fully independent from the funders.

Competing interests None declared.

Ethics approval School of Medicine Research Ethics Committee at Cardiff University (reference no: 15/08).

Provenance and peer review Not commissioned; externally peer reviewed.

Data sharing statement № additional unpublished data are available outside the research team.

Open Access This is an Open Access article distributed in accordance with the Creative Commons Attribution Non Commercial (CC BY-NC 4.0) license, which permits others to distribute, remix, adapt, build upon this work non-commercially, and license their derivative works on different terms, provided the original work is properly cited and the use is non-commercial. See: http://creativecommons.org/ licenses/by-nc/4.0/

(c) Article author(s) (or their employer(s) unless otherwise stated in the text of the article) 2017. All rights reserved. No commercial use is permitted unless otherwise expressly granted.

\section{REFERENCES}

1. Nason GJ, Liddy S, Murphy T, et al. A cross-sectional observation of burnout in a sample of Irish junior doctors. Ir J Med Sci 2013;182:595-9.

2. O'Donnell M, Noad R, Boohan M, et al. Foundation programme impact on junior doctor personality and anxiety in Northern Ireland. Ulster Med J 2012;81:19-25.

3. Markwell AL, Wainer $Z$. The health and wellbeing of junior doctors: insights from a national survey. Med J Aust 2009;191:441-4.

4. Monrouxe LV, Grundy L, Mann M, et al. How prepared are UK medical graduates for practice? A rapid review of the literature 2009-2014. BMJ Open 2017;7.

5. Lundin RM, Bashir K, Bullock A, et al. "l'd been like freaking out the whole night": exploring emotion regulation based on junior doctors' narratives. Adv Health Sci Educ Theory Pract 2017. Epub ahead of print 21 Mar 2017.

6. Ishak W, Nikravesh R, Lederer S, et al. Burnout in medical students: a systematic review. Clin Teach 2013;10:242-5.

7. Gunasingam N, Burns K, Edwards J, et al. Reducing stress and burnout in junior doctors: the impact of debriefing sessions. Postgrad Med J 2015;91:182-7.

8. Feeney S, O'Brien $\mathrm{K}, \mathrm{O}$ 'Keeffe N, et al. Practise what you preach: health behaviours and stress among non-consultant hospital doctors. Clin Med 2016;16:12-18.

9. Wege N, Muth T, Li J, et al. Mental health among currently enrolled medical students in Germany. Public Health 2016;132:92-100.

10. Cuttilan AN, Sayampanathan AA, Ho RC. Mental health issues amongst medical students in Asia: a systematic review [2000-2015]. Ann Transl Med 2016;4:72.

11. Cecil J, McHale C, Hart J, et al. Behaviour and burnout in medical students. Med Educ Online 2014;19:25209.

12. Dahlin M, Fjell J, Runeson B. Factors at medical school and work related to exhaustion among physicians in their first postgraduate year. Nord J Psychiatry 2010;64:402-8.

13. Prins JT. PhD Thesis: burnout among Dutch medical residents. GMS Z Med Ausbild 2010;27:Doc15-Doc15. 
14. Richter A, Kostova P, Harth V, et al. Children, care, career - a crosssectional study on the risk of burnout among German hospital physicians at different career stages. J Occup Med Toxicol 2014;9.

15. Dyrbye LN, West CP, Satele D, et al. Burnout among U.S. medical students, residents, and early career physicians relative to the general U.S. population. Acad Med 2014;89:443-51.

16. Ripp J, Fallar R, Babyatsky M, et al. Prevalence of resident burnout at the start of training. Teach Learn Med 2010;22:172-5.

17. Shanafelt TD, Bradley KA, Wipf JE, et al. Burnout and self-reported patient care in an internal medicine residency program. Ann Intern Med 2002;136:358-67.

18. Seo JH, Kim HJ, Kim BJ, et al. Educational and relational stressors associated with Burnout in Korean medical students. Psychiatry Investig 2015;12:451-8.

19. Dyrbye LN, Thomas MR, Massie FS, et al. Burnout and suicidal ideation among U.S. medical students. Ann Intern Med 2008;149:334-41.

20. Dyrbye L, Shanafelt T. A narrative review on burnout experienced by medical students and residents. Med Educ 2016;50:132-49.

21. Newbury-Birch D, Kamali F. Psychological stress, anxiety, depression, job satisfaction, and personality characteristics in preregistration house officers. Postgrad Med J 2001;77:109-11.

22. Firth-Cozens J, Greenhalgh J. Doctors' perceptions of the links between stress and lowered clinical care. Soc Sci Med 1997:44:1017-22.

23. Tyssen R, Vaglum P, Grønvold NT, et al. Factors in medical school that predict postgraduate mental health problems in need of treatment. A nationwide and longitudinal study. Med Educ $2001 ; 35: 110-20$

24. Ishak WW, Lederer S, Mandili C, et al. Burnout during residency training: a literature review. J Grad Med Educ 2009;1:236-42.

25. Peisah C, Latif E, Wilhelm K, et al. Secrets to psychological success: why older doctors might have lower psychological distress and burnout than younger doctors. Aging Ment Health 2009;13:300-7.

26. Willcock SM, Daly MG, Tennant CC, et al. Burnout and psychiatric morbidity in new medical graduates. Med J Aust 2004;181:357-60.

27. Parr JM, Pinto N, Hanson M, et al. Medical graduates, tertiary hospitals, and burnout: a longitudinal cohort study. Ochsner $J$ 2016;16:22-6.

28. McManus IC, Keeling A, Paice E. Stress, burnout and doctors' attitudes to work are determined by personality and learning style: a twelve year longitudinal study of UK medical graduates. BMC Med 2004;2:29.

29. Adams K, Hean S, Sturgis P, et al. Investigating the factors influencing professional identity of first-year health and social care students. Learning in Health and Social Care 2006;5:55-68.

30. Burford B. Group processes in medical education: learning from social identity theory. Med Educ 2012;46:143-52.

31. Irvine D. Patients want to be sure that they have a good doctor: Relating public expectations to professional regulation, professional identity and professionalism. In: Cruess R, Cruess S, Steinert Y, eds. Teaching medical professionalism. 2nd edition. Cambridge: Supporting the development of a professional identityCambridge University Press, 2016

32. Monrouxe LV. Identity, identification and medical education: why should we care? Med Educ 2010;44:40-9.

33. Tajfel H, Turner J. The Social Identity Theory of Intergroup Behavior. In: Jost J, Sidanius J, eds. Political psychology: Key readings Key readings in social psychology. 479. New York, NY, US: Psychology Press, 2004.

34. Lesage FX, Berjot S, Altintas E, et al. Burnout among occupational physicians: a threat to occupational health systems?--A nationwide cross-sectional survey. Ann Occup Hyg 2013;57:913-9.

35. Berjot S, Girault-Lidvan N, Gillet N. Appraising stigmatization and discrimination: construction and validation of a questionnaire assessing threat and challenge appraisals to personal and social identity. Identity 2012;12:191-216.

36. Losch A, Grafton B, MacLeod C. One small step towards the spider, but a giant leap in anxiety: Biased attentional responding to spider stimuli causally contributes to the rate of growth in state anxiety during spider approach. Aust J Psychol 2016;68:178-90.

37. Bjelland I, Dahl AA, Haug TT, et al. The validity of the hospital anxiety and depression scale. An updated literature review. J Psychosom Res 2002;52:69-77.

38. Cooke GP, Doust JA, Steele MC. A survey of resilience, burnout, and tolerance of uncertainty in Australian general practice registrars. BMC Med Educ 2013;13:6.

39. Puricelli O, Callegari S, Pavacci V, et al. Connection between anxiety and burnout in health professions. Minerva Psichiatrica 2008;49:255-66.
40. Zhou J, Yang Y, Qiu X, et al. Relationship between anxiety and burnout among Chinese Physicians: a moderated mediation model. PLOS One 2016;11:15:e0157013.

41. Epstein RM, Privitera MR. Doing something about physician burnout. Lancet 2016;388:2216-7.

42. West CP, Dyrbye LN, Erwin PJ, et al. Interventions to prevent and reduce physician burnout: a systematic review and meta-analysis. Lancet 2016;388:2272-81.

43. Dyrbye LN, Thomas MR, Harper W, et al. The learning environment and medical student burnout: a multicentre study. Med Educ 2009;43:274-82.

44. Wasson LT, Cusmano A, Meli L, et al. Association between learning environment interventions and medical student well-being: a systematic review. JAMA 2016;316:2237-52.

45. Reed DA, Shanafelt TD, Satele DW, et al. Relationship of pass/ fail grading and curriculum structure with well-being among preclinical medical students: a multi-institutional study. Acad Med 2011;86:1367-73.

46. GMC. Clinical placements for medical students: advice supplementary to tomorrow's doctors(2009). London: General Medical Council, 2011.

47. Bates C. Don't get sick in August! Doctors warn patient safety at risk as trainees take to the wards. The Daily Mail 2011

48. Jones OM, Okeke C, Bullock A, et al. 'He's going to be a doctor in August': a narrative interview study of medical students' and their educators' experiences of aligned and misaligned assistantships. BMJ Open 2016;6:e011817.

49. Vaughan L, McAlister G, Bell D. 'August is always a nightmare': results of the Royal College of Physicians of Edinburgh and Society of Acute Medicine August transition survey. Clin Med 2011;11:322-6.

50. GMC. Tomorrow's doctors: general medical council. 2015;2009 http://www.gmcuk.org/Tomorrow_s_Doctors_to_be_withdrawn_on 01 01_2016.pdf 62052357.pdf

51. Braniff C, Spence RA, Stevenson M, et al. Assistantship improves medical students' perception of their preparedness for starting work. Med Teach 2016;38:51-8.

52. Hawkins A, Stanton A, Forbes K. An extended assistantship for finalyear students. Clin Teach 2015;12:305-9.

53. Monrouxe L, Bullock A, Cole J, et al. How prepared are UK medical graduates for practice? Final report from a programme of research commissioned by the general medical council http:// www.gmc-uk.org/How_Prepared_are_UK_Medical_Graduates_for_ Practice_SUBMITTED_Revised_140614.pdf_58034815.pdf: GMC, 2014.

54. Crossley JG, Vivekananda-Schmidt P. Student assistantships: bridging the gap between student and doctor. Adv Med Educ Pract 2015;6:447-57.

55. Lightman E, Kingdon S, Nelson M. A prolonged assistantship for final-year students. Clin Teach 2015;12:115-20.

56. Fullbrook A, Ross M, Mellanby $E$, et al. Initial experiences of a student assistantship. Clin Teach 2015;12:310-4.

57. Burford B, Ellis E, Williamson A, et al. Learning opportunities in 'student assistantships'. Clin Teach 2015;12:121-7.

58. Brown R, Condor S, Mathews A, et al. Explaining intergroup differentiation in an industrial organization. $J$ Occup Organ 1986;59:273-86.

59. Hamilton M. The assessment of anxiety states by rating. $\mathrm{Br} \mathrm{J} \mathrm{Med}$ Psychol 1959;32:50-5.

60. Kristensen TS, Borritz M, Villadsen E, et al. The Copenhagen burnout inventory: a new tool for the assessment of burnout. Work Stress 2005;19:192-207.

61. Campos JADB, Carlotto MS, Marôco J. Copenhagen burnout inventory - student version: adaptation and transcultural validation for Portugal and Brazil. Psicologia: Reflexão e Crítica 2013;26:87-97.

62. Faraway JJ. Extending the linear model with R: generalized linear, mixed effects and nonparametric regression models: CRC press, 2016.

63. Development Core Team. $R$ : A language and environment for statistical computing. R Foundation for Statistical Computing. Vienna, Austria, 2014

64. Bates D, Mächler M, Bolker B, et al. Fitting linear mixed-effects models using Ime4. arXiv preprint arXiv:1406.5823 2014

65. Nakagawa S, Schielzeth H. A general and simple method for obtaining R2 from generalized linear mixed-effects models. Methods Ecol Evol 2013;4:133-42.

66. Haslam SA, Reicher S. Stressing the group: social identity and the unfolding dynamics of responses to stress. $J$ Appl Psychol 2006;91:1037-52.

67. Luyckx K, Duriez B, Klimstra TA, et al. Identity statuses in young adult employees: prospective relations with work engagement and burnout. J Vocat Behav 2010;77:339-49. 
68. Fisherman S. Professional identity and burnout among preschool, elementary, and post-elementary school teachers in Israel. Journal of Curriculum and Teaching 2015;4:1-13.

69. Steyn C, De Klerk JJ. Serving up the self: Role identity and burnout in client service environments. SA Journal of Industrial Psychology 2015;41.

70. Iversen A, Rushforth B, Forrest K. Practice the competent novice how to handle stress and look after your mental health. BMJ 2009;338.

71. Firth-Cozens J. Source of stress in women junior house officers. BMJ 1990;301:89-91.

72. Blanchard P, Truchot D, Albiges-Sauvin L, et al. Prevalence and causes of burnout amongst oncology residents: a comprehensive nationwide cross-sectional study. Eur J Cancer 2010;46:2708-15.

73. Purvanova RK, Muros JP. Gender differences in burnout: a metaanalysis. J Vocat Behav 2010;77:168-85.
74. Hillhouse JJ, Adler CM, Walters DN. A simple model of stress, burnout and symptomatology in medical residents: A longitudinal study. Psychol Health Med 2000;5:63-73.

75. Monrouxe LV, Rees CE, Dennis I, et al. Professionalism dilemmas, moral distress and the healthcare student: insights from two online UK-wide questionnaire studies. BMJ Open 2015;5:e007518.

76. Durkin J. UK graduates 2015 provisional registration report. London: General Medical Council, 2016.

77. The UK Foundation Programme Office. Foundation programme 2016 recruitment stats and facts interim report march 2016. http://www. foundationprogramme.nhs.uk/download.asp?file=stats_and_facts_ fp2016_interim_report_april_2016_v4.pdf

78. Cruess RL, Cruess SR, Steinert Y. Teaching medical professionalism: supporting the development of a professional identity. 309. Cambridge: Cambridge University Press, 2016. 